\title{
Improved CPAS Photogrammetric Capabilities for Engineering Development Unit (EDU) Testing
}

\author{
Eric S. Ray ${ }^{1}$ \\ Jacobs Engineering, Houston, TX, 77058 \\ David R. Bretz ${ }^{2}$ \\ Barrios Technology, Houston, TX, 77058
}

This paper focuses on two key improvements to the photogrammetric analysis capabilities of the Capsule Parachute Assembly System (CPAS) for the Orion vehicle. The Engineering Development Unit (EDU) system deploys Drogue and Pilot parachutes via mortar, where an important metric is the muzzle velocity. This can be estimated using a high speed camera pointed along the mortar trajectory. The distance to the camera is computed from the apparent size of features of known dimension. This method was validated with a ground test and compares favorably with simulations. The second major photogrammetric product is measuring the geometry of the Main parachute cluster during steady-state descent using onboard cameras. This is challenging as the current test vehicles are suspended by a single-point attachment unlike earlier stable platforms suspended under a confluence fitting. The mathematical modeling of fly-out angles and projected areas has undergone significant revision. As the test program continues, several lessons were learned about optimizing the camera usage, installation, and settings to obtain the highest quality imagery possible.

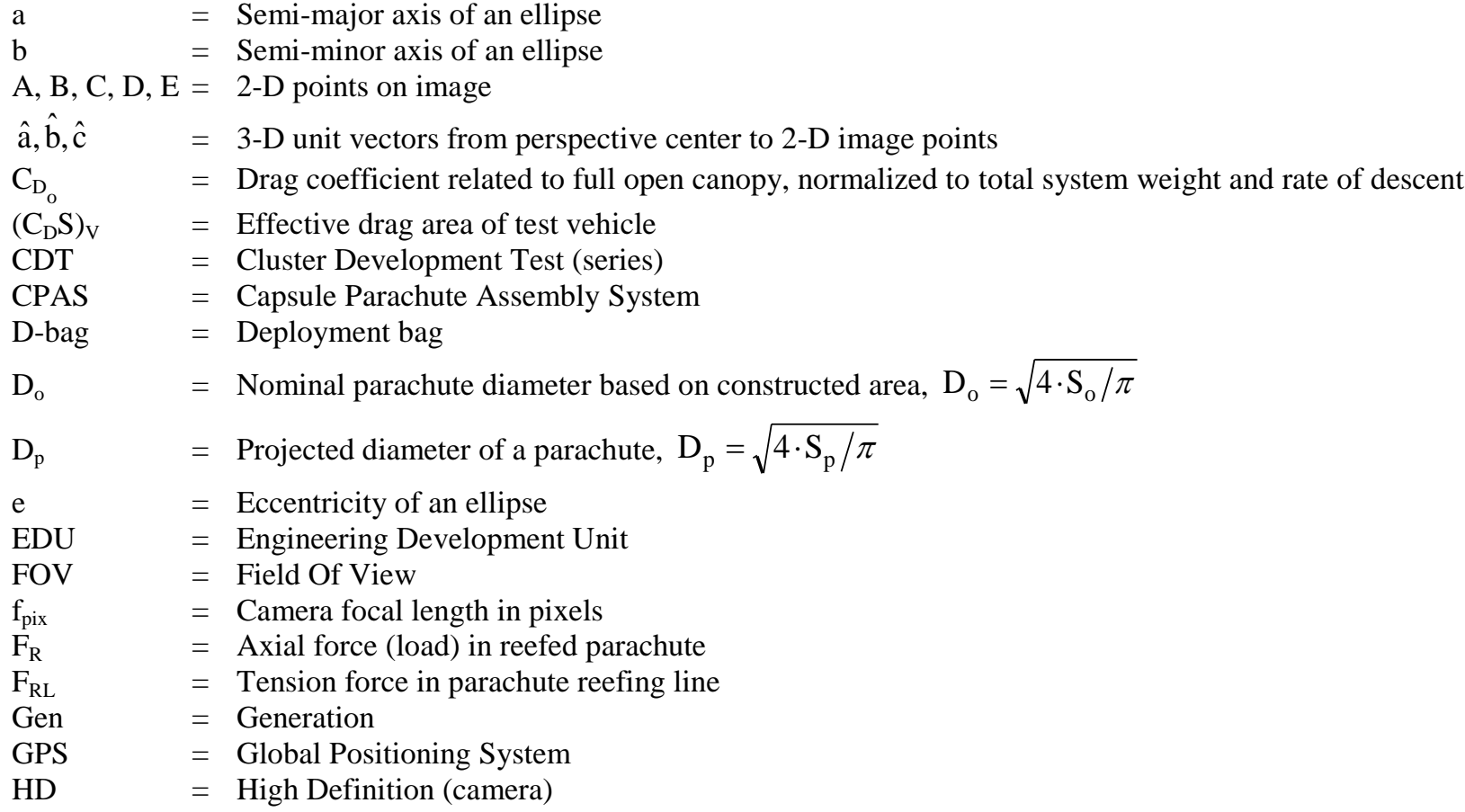

\footnotetext{
${ }^{1}$ Analysis Engineer, Aeroscience and Flight Dynamics, 2224 Bay Area Blvd, Houston, TX, AIAA Member.

${ }^{2}$ Image Science \& Analysis Group, JSC-KX, non-member.
} 


$\begin{array}{ll}\mathrm{L}_{\mathrm{in}} & =\text { Known size of the lid in inches } \\ \mathrm{L}_{\mathrm{pix}} & =\text { Diameter of the lid in pixels } \\ \mathrm{L}_{\mathrm{R}} & =\text { Reefing line length } \\ \mathrm{L}_{\mathrm{s}} & =\text { Suspension line length } \\ \mathrm{MPCV} & =\text { Multi Purpose Crew Vehicle (Orion) } \\ \mathrm{N}_{\mathrm{c}} & =\text { Number of parachutes in a cluster } \\ \mathrm{N}_{\mathrm{G}} & =\text { Number of gores in a parachute canopy } \\ \mathrm{P}_{\mathrm{i}} & =\text { Skirt perimeter for parachute i } \\ \mathrm{PC} & =\text { Perspective Center } \\ \mathrm{PP} & =\text { Principal Point } \\ \mathrm{PSF} & =\text { Parachute Shape Factor } \\ \rho & =\text { Humidity-corrected atmospheric density } \\ \mathrm{RC} & =\text { Ramp Clear (usually chosen as start of test) } \\ \mathrm{SD} & =\text { Standard Definition (camera) } \\ \mathrm{S} / \mathrm{N} & =\text { Serial Number } \\ \mathrm{S}_{\mathrm{o}} & =\text { Parachute Canopy open reference area based on constructed shape } \\ \mathrm{S}_{\mathrm{p}} & =\text { Projected frontal canopy area } \\ \mathrm{S}_{\mathrm{p}_{\mathrm{c}}} & =\text { Projected frontal canopy area of a cluster } \\ S_{\mathrm{Ring}} & =\text { Scale between physical length and pixels at plane of chosen Ring } \\ S_{\text {skirt }} & =\text { Scale between physical length and pixels at plane of parachute skirt } \\ \theta_{\mathrm{l}}, \text { theta } & =\text { Fly-out angle for parachute i } \\ \mathrm{UTC} & =\text { Coordinated Universal Time } \\ \mathrm{V}_{\mathrm{e}} & =\text { Equilibrium rate of descent } \\ \mathrm{W}_{\mathrm{T}} & =\text { Total weight of test vehicle and parachutes } \\ \text { YPG } & =\text { Yuma Proving Ground }\end{array}$

\section{Introduction}

DHOTOGRAMMETRIC analysis plays an important role in the Capsule Parachute Assembly System (CPAS) test program. The Engineering Development Unit (EDU) flight test vehicles each use a parachute compartment with similar structural and functional properties to the production Orion Multi Purpose Crew Vehicle (MPCV). The system is described in Ref. 1. Analysis of video and still imagery helps verify the performance of the system.

A previous publication focused on explaining the method of measuring the Main parachute flyout angles and projected areas. ${ }^{2}$ This procedure has been updated to account for challenges posed by new test vehicles. In addition, this paper examines how photogrammetry has been expanded to other aspects of CPAS flight tests.

A typical camera suite for the missile-shaped Parachute Compartment Drop Test Vehicle (PCDTV) is shown in Figure 1. The cameras in bays $\mathrm{A}$ and $\mathrm{F}$ observe Drogue and Pilot parachute mortar deployment. One bay observes the event in high-speed to track the mortar

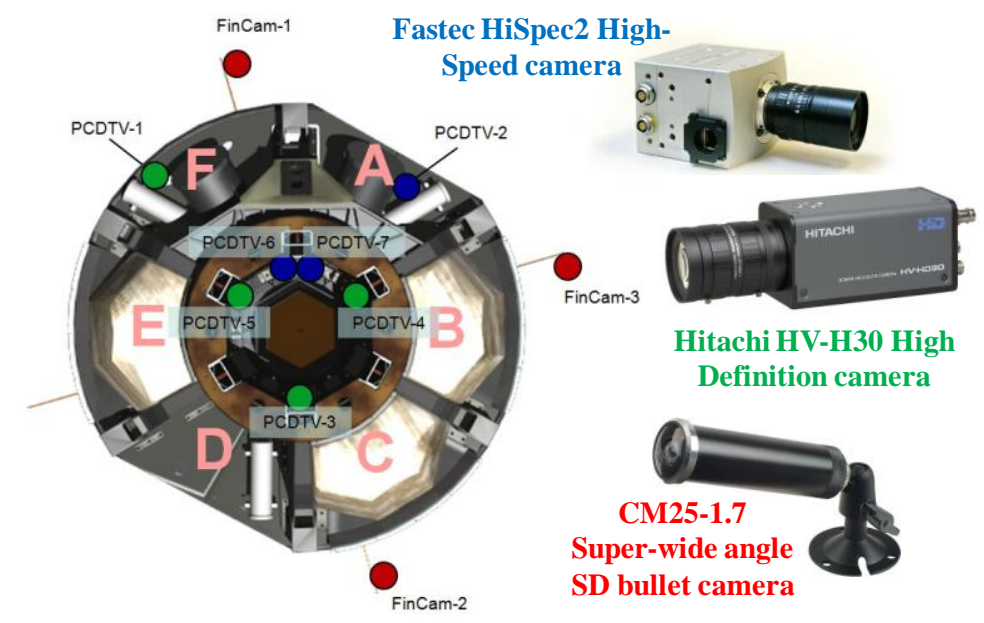

Figure 1. Typical cameras and locations (circles) used on a PCDTV test.

trajectory while the other has HD coverage at 60 frames per second (progressive). A series of cameras are located along the perimeter of the central tunnel, looking upward at parachute deployment and performance. Also, small "bullet" cameras are mounted to the stabilization fins pointing inward to observe the parachute retention systems and deployment. The "boilerplate" Parachute Test Vehicle (PTV) has a similar suite of cameras with the exception that the capsule-shaped PTV lacks fins on which to mount bullet cameras. 


\section{EDU Drogue Mortar Ejection Velocity}

A recent innovation is the use of photogrammetric analysis to determine the Drogue mortar ejection velocity in flight tests using high-speed video along the mortar boresight. The ejection velocity of a Drogue parachute assembly from its mortar canister is a key factor in determining the time to parachute inflation. The peak loads produced during inflation are highly sensitive to the amount of time the vehicle spends in free fall. Therefore, accurate measurements of ejection velocity will improve modeling Drogue loads. The mortar system has requirements for minimum muzzle velocity yet must not producing excessive reaction loads.

All high-speed video taken to date by CPAS used the Fastec HiSpec 2 model camera. ${ }^{3}$ This unit provides flexibility in frame rate and resolution to obtain footage of a desired duration. This camera also features the capability to split its onboard storage into multiple partitions to record multiple events, each activated by an external trigger. This allows a single camera to observe the high-speed ejection of a CPAS Drogue parachute and later a CPAS Pilot parachute.

A summary of this analysis to date is listed in Table 1 . The velocity results were all derived over a consistent range of distances and assuming the same camera principal point location.

Table 1. EDU Drogue Mortar Photogrammetric Results

\begin{tabular}{|c|c|c|c|c|c|c|c|}
\hline Test & Test Vehicle & $\begin{array}{l}\text { Mortar } \\
\text { Location }\end{array}$ & $\begin{array}{c}\text { Propellant } \\
\text { load } \\
(\mathrm{g})\end{array}$ & $\begin{array}{c}\text { High } \\
\text { Speed } \\
\text { Camera } \\
\text { Serial } \\
\text { Number }\end{array}$ & $\begin{array}{c}\text { Calibrated } \\
\text { Camera } \\
\text { Focal } \\
\text { Length } \\
\text { (pixels) }\end{array}$ & $\begin{array}{l}\text { Distance } \\
\text { Range for } \\
\text { Speed } \\
\text { Calculation } \\
\text { (ft) }\end{array}$ & $\begin{array}{c}\text { Regressed } \\
\text { Avg. } \\
\text { Mortar } \\
\text { Speed } \\
\text { (ft/s) }\end{array}$ \\
\hline CDT-3-1 & PCDTV & Bay A & 74.5 & (unk.) & $1296^{*}$ & 7 to 28 & 140 \\
\hline CDT-3-2 & PCDTV & Bay F & 62.0 & (unk.) & $1296^{*}$ & 2.5 to 24 & 148 \\
\hline CDT-3-3 & PTV Boilerplate & Bay A & 62.0 & $130(7 \mathrm{~A})$ & $1296^{*}$ & 2.5 to 27 & 123 \\
\hline CDT-3-4 & PCDTV & Bay F & 62.0 & $130(7 \mathrm{~A})$ & $1296^{*}$ & 7 to $93^{* *}$ & 144 \\
\hline CDT-3-5 & PTV Boilerplate & Bay A & 62.0 & $129(6 \mathrm{~A})$ & 1305 & 2.5 to 32 & 140 \\
\hline CDT-3-6 & PCDTV & Bay F & 62.0 & & Data - H & Cameras Fail & \\
\hline
\end{tabular}

\section{A. Drogue Mortar Deployment Tracking Method}

Some representative frames of the Drogue deployment high-speed video from CDT-3-1 are shown in Figure 2. The rigid lid attached to the front of the deployment bag (D-bag) projects a semi-major axis at any orientation, which is equal to the known lid diameter at any frame. Points along the edge are tracked as shown in Figure 3.

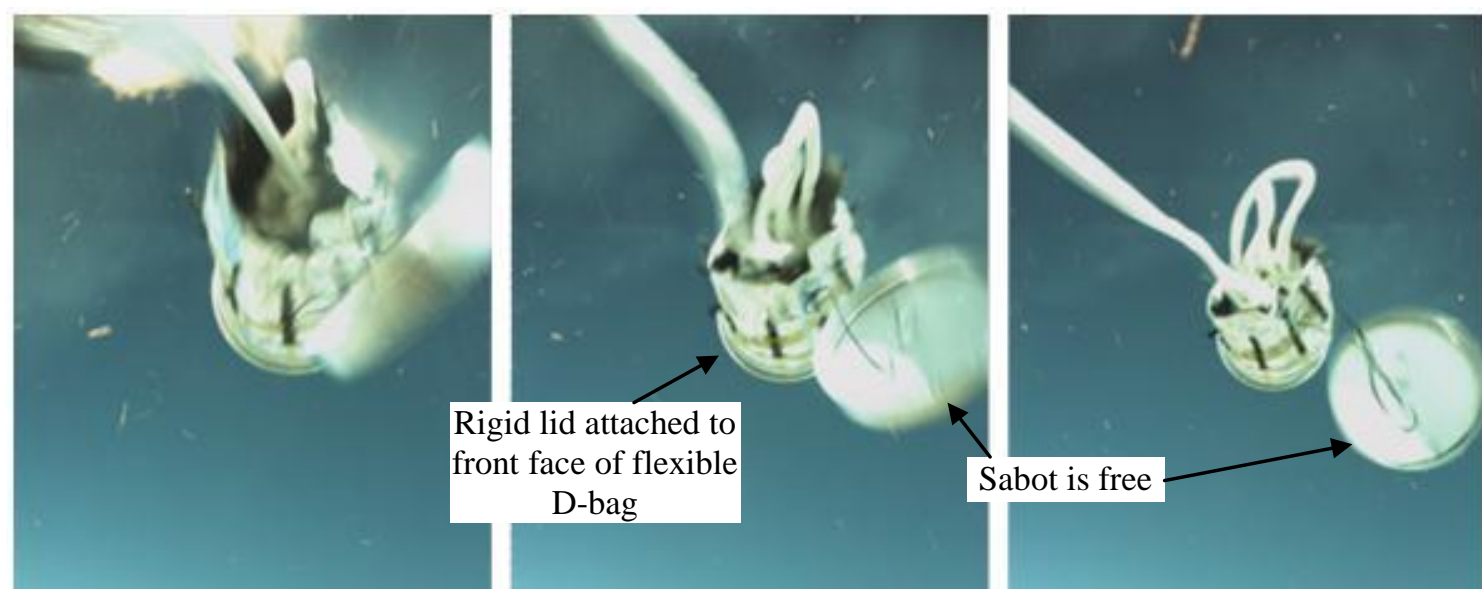

Figure 2. Drogue mortar firing high-speed video from CDT-3-1. 

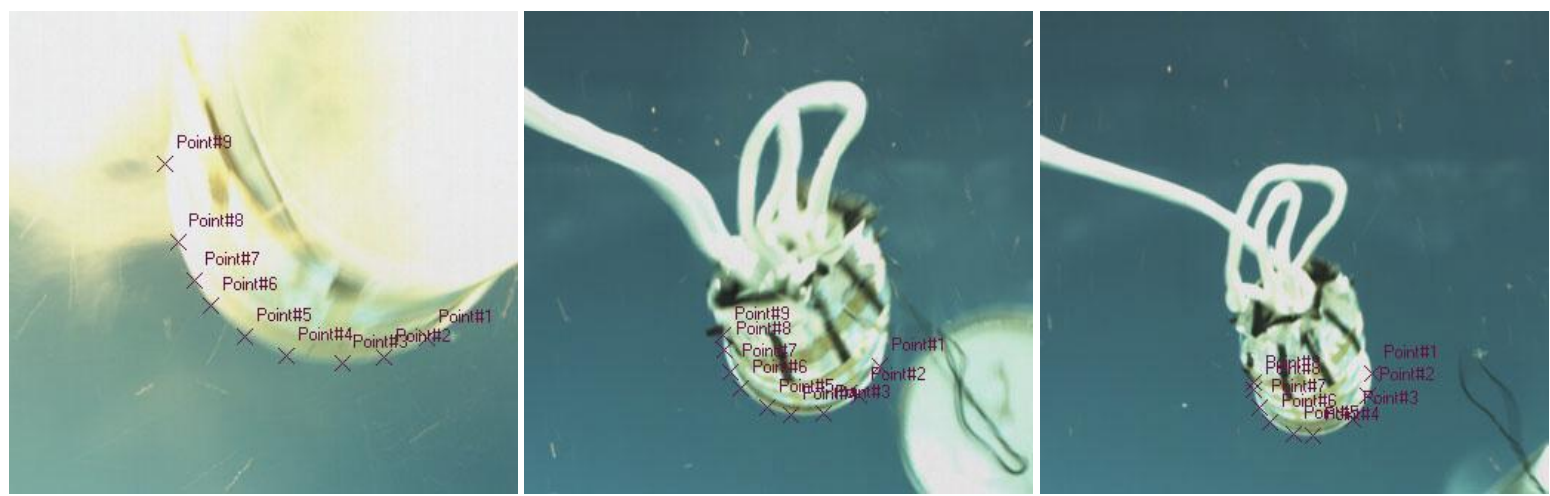

Figure 3. Drogue mortar lid tracking.

At each frame, the tracked points are used to fit an ellipse centered at coordinates $\left[\mathrm{X}_{\mathrm{c}}, \mathrm{Y}_{\mathrm{c}}\right]$ of semi-major axis length a, semi-minor axis length $b$, and eccentricity e. The parameters of each ellipse are examined graphically in order to reject any frames where the fit is invalid or inconsistent. The range (in inches) from the camera to the lid is calculated based on these variables according to Eq. 1:

- Diameter of the lid in pixels, $\mathrm{L}_{\mathrm{pix}}=2 \cdot \mathrm{a}$

- Known size of the lid in inches, $\mathrm{L}_{\mathrm{in}}=17.75$ inches

- Camera focal length in pixels, $\mathrm{f}_{\text {pix }}$

- Distance of the lens behind the starting position of the lid, $\mathrm{d}_{\mathrm{in}}$

$$
\text { Range }=\mathrm{f}_{\text {pix }} \cdot \frac{\mathrm{L}_{\text {in }}}{\mathrm{L}_{\text {pix }}}-\mathrm{d}_{\text {in }}
$$

Like all photogrammetrics, this method is dependent on the quality of the original imagery. To this end, efforts were made to adjust the camera settings. Decreasing the exposure duration on the high speed video prevents overexposure, better freezes the motion of objects in the near field, and prevents the depth of field (focus range) from including dirt on the lens itself. The raw imagery produced is necessarily darker, but simple post-processing steps are used to boost contrast to useful levels. The high-speed images from CDT-3-5 in Figure 4 clearly show a sharper image than from CDT-3-1, to the point of resolving the indentations on the sabot.

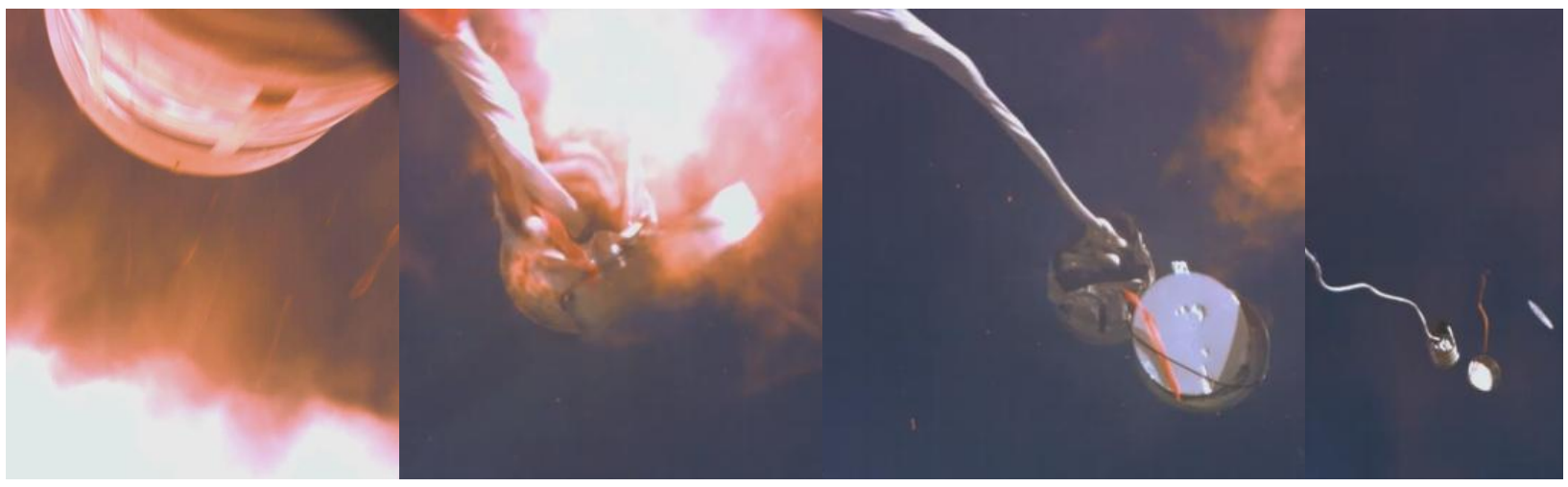

Figure 4. Improved sharpness in CDT-3-5 high-speed footage.

The calculated range to the camera for each frame is then plotted against time, which is available on from the video timecode. An example trace from CDT-3-5 is shown in Figure 5, where the time is relative to Drogue mortar fire. A linear regression of the slope provides an approximate velocity. This is sensitive to the range of points chosen. In this case, the points until about 32 feet provide are thought to provide a better estimate of muzzle velocity than the smaller velocity from the entire range up to 100 feet. Points are missing in the mid-range due to the sabot obscuring the D-bag lid. 


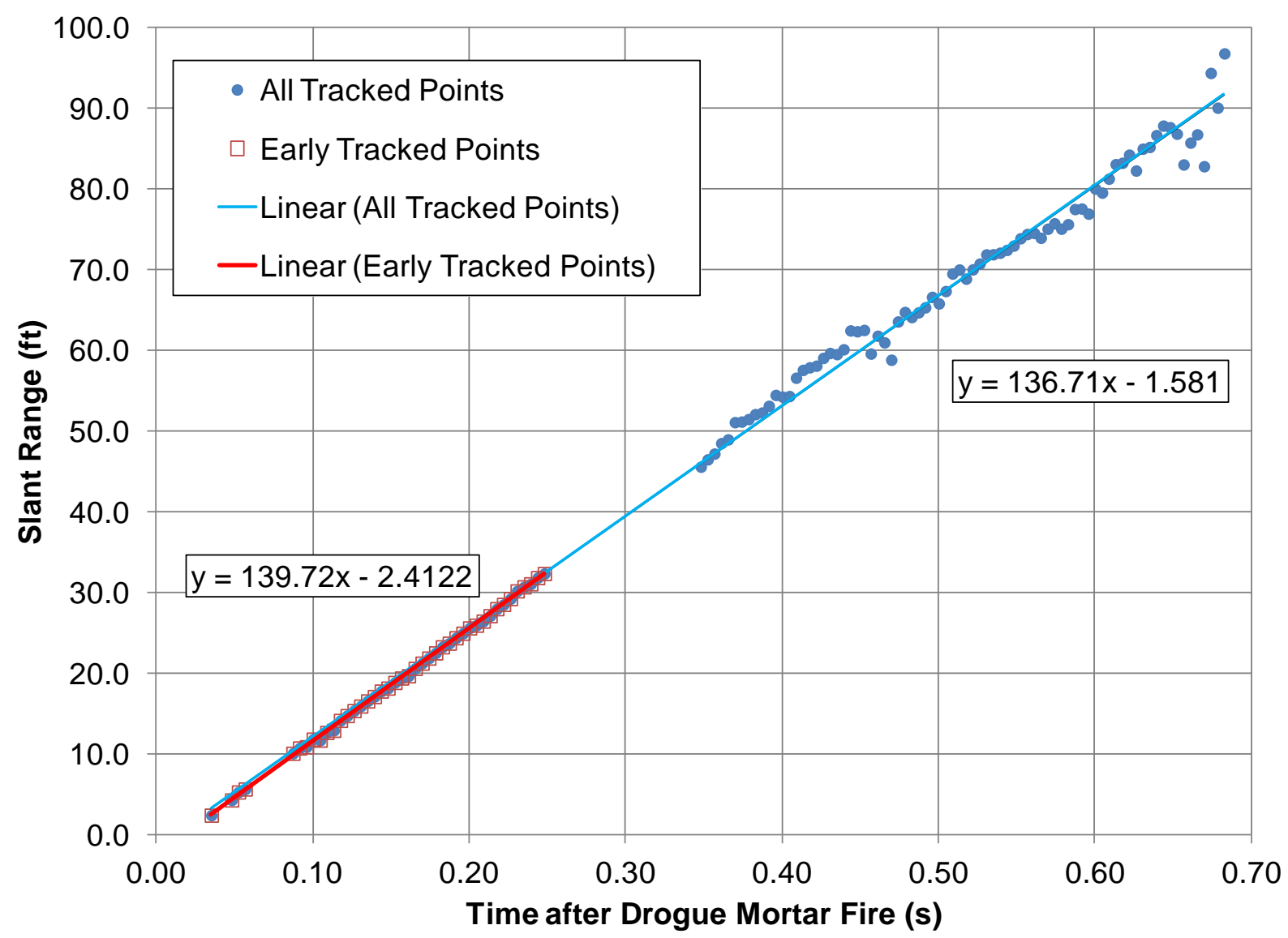

Figure 5. CDT-3-5 Drogue mortar trajectory distance vs. time.

\section{B. Mortar Deployment Validation Ground Test}

This method was validated via an indoor horizontal mortar ground test at the General Dynamics facility in Bothwell, WA. The CPAS high-speed camera was placed in a same relative location and orientation as during a flight test. Other high-speed cameras were placed perpendicular to the direction of travel in order to track the Drogue D-bag against a background with marked locations. The test setup is shown in Figure 6 and sample imagery from the perspective of the high-speed camera is in Figure 7.
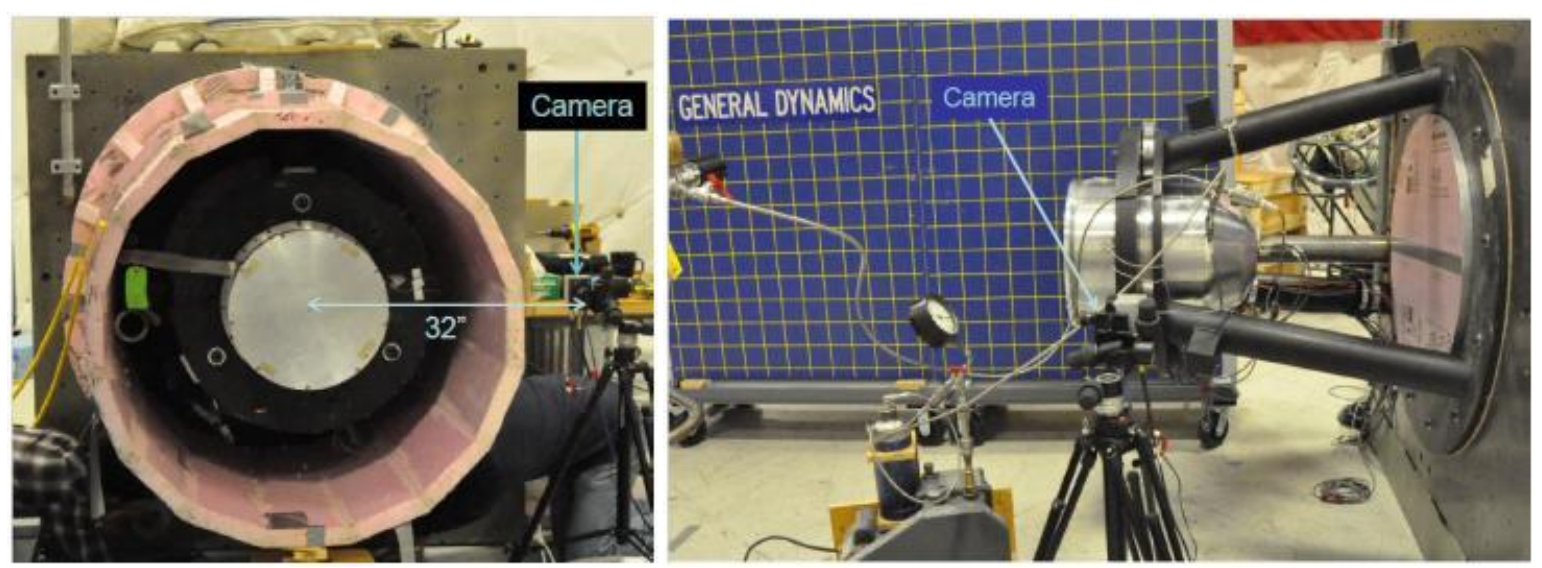

Figure 6. Indoor ground test setup. 

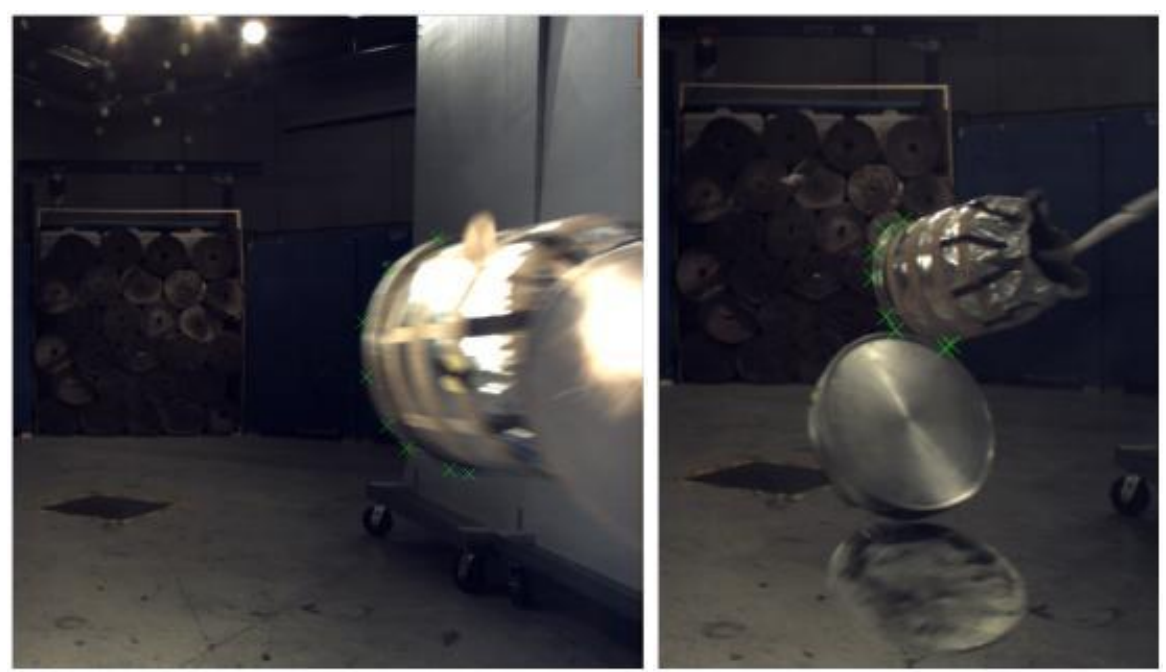

The computed velocity using the flight test method was confirmed similar to the velocity computed from the orthogonal cameras.

Figure 7. Sample tracked high-speed footage from ground test.

\section{Observations from Chase Aircraft}

Because the test vehicle descends rapidly during each flight, a series of chase aircraft are used to document critical events which are generally out of range of cameras at the surface of Yuma Proving Ground (YPG). A NASA C-12 King Air observes the mated test article extraction and PTV or PCDTV separation but is usually out of visual range by the end of the programmer phase. To fill this gap in coverage, a NASA T-34C aircraft stationed at Dryden Flight Research Center is now staged at the Drogue deployment altitude to capture high quality images of Drogue deployment. ${ }^{4}$ Sample images are shown in Figure 8. Also indicated are the photogrammetric markings on the PTV which allow even the casual observer to determine the vehicle attitude. Finally, it is regular practice to stage a YPGbased UH-1H helicopter at the Main parachute deployment altitude with NASA and/or YPG photographers. This allows for orthogonal views of the reefed stages for over-inflation angle studies. The UH-1H then follows the vehicle through touchdown observing Main cluster dynamics (see Section III) and close-up views of any parachute damage. 

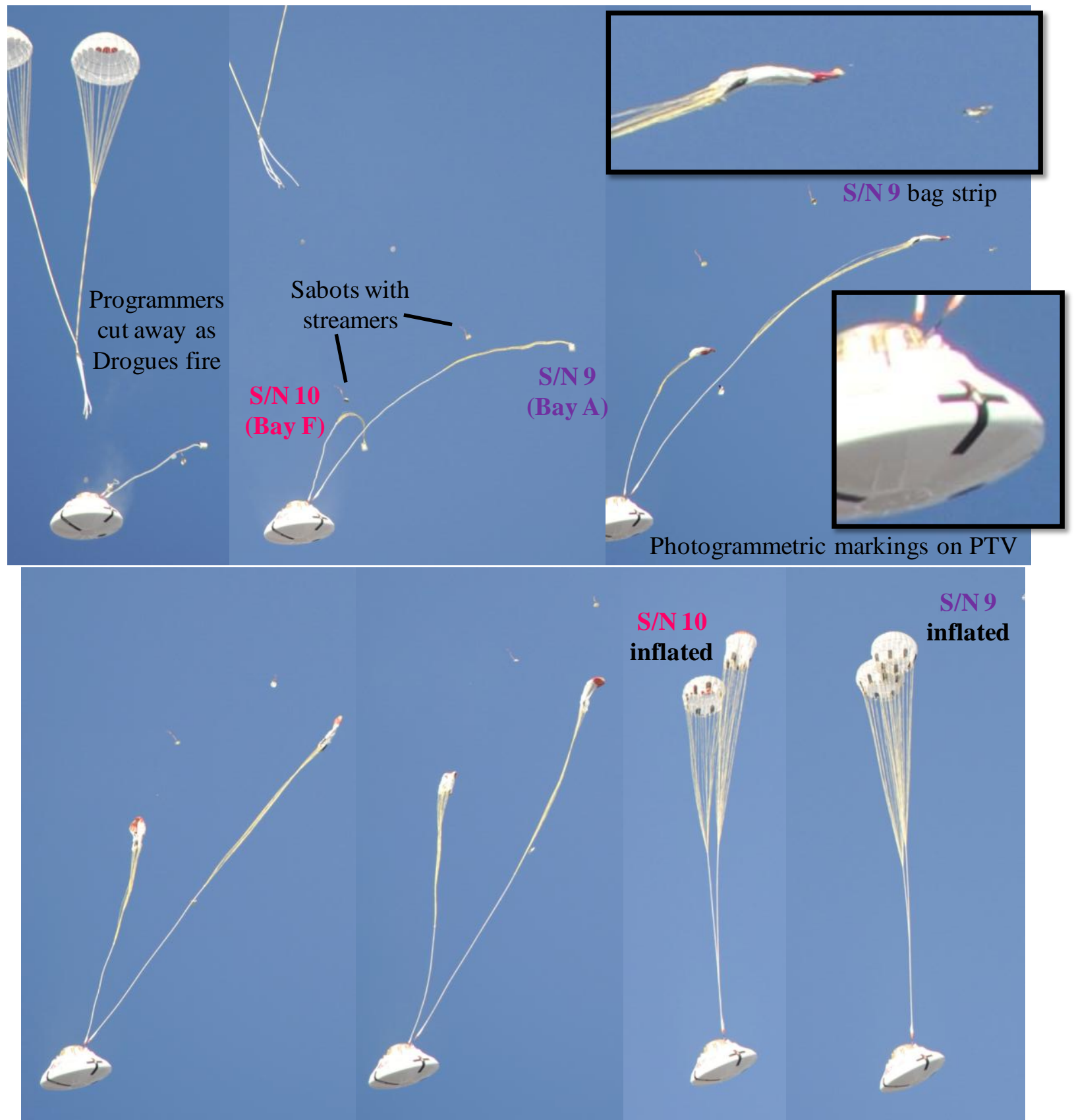

Figure 8. Still photographs of CDT-3-5 Drogue deployment from NASA T-34C chase aircraft.

Correlating the still images to other data requires knowledge of the time each picture was taken. The cameras used generally save both an internal clock time and a GPS time to the image file metadata. However, some adjustments must be made to this data to obtain a sufficient level of precision, as explained in Ref. 5. 
The largest error source with the high-speed mortar tracking method is that a linear fit of distance vs. time cannot establish if the D-bag is accelerating or decelerating depending on whether the mortared assembly is launched with or against a relative flow field. To simulate the aerodynamic effects on the mortar deployment, a model was created by Dr. Vladimir Drozd of Airborne Systems. This code includes a finite element model of the deploying riser and suspension lines (e.g. "line sail"). It is well known that the deploying lines will affect the position and orientation of the canopy deployment. ${ }^{6,7}$

Dr. Drozd satisfactorily reconstructed the deployment of CDT-3-1 and CDT-3-2 using the recorded vehicle state and atmospheric conditions at mortar deployment. ${ }^{8}$ In both cases, the best match of time to line stretch and deploying line shape resulted from a mortar muzzle velocity of $140 \mathrm{ft} / \mathrm{s}$. A reconstructed Drogue trajectory from CDT-3-1 is shown in Figure 9 and displays realistic shapes of the deploying lines.

The study noted that even given a perfect history of distance vs. time, it is challenging to determine an exact initial velocity from either a linear or quadratic fit of the output. Therefore, a mortar deployment model should be used in conjunction with photogrammetric analysis. The current model is currently being incorporated into the high-fidelity parachute model common to NASA and Lockheed Martin Orion simulations.

\section{EDU Main Parachute Measurements}

A summary of CPAS tests to date using the added porosity Main parachute design is shown in Table 2. An "X" indicates that the given photogrammetric analysis has been completed. Selected results are presented in the following sections to show general trends and lessons learned.

Table 2. CPAS Main Parachute Photogrammetric Status

\begin{tabular}{|c|c|c|c|c|c|}
\hline \multirow[b]{2}{*}{ Flight Test } & \multirow[b]{2}{*}{ Test Vehicle } & \multirow[b]{2}{*}{$\begin{array}{l}\text { Number } \\
\text { of Mains }\end{array}$} & \multicolumn{3}{|c|}{ Status of Photogrammetric Analysis } \\
\hline & & & Fly-Out Angles & $\begin{array}{l}\text { Parachute } \\
\text { Collisions }\end{array}$ & $\begin{array}{c}\text { Projected } \\
\text { Diameter/Area }\end{array}$ \\
\hline CDT-2-2 & Platform & $2^{*}$ & $\mathrm{X}$ & $\mathrm{X}$ & $\mathrm{X}(2-\mathrm{D})$ \\
\hline CDT-2-3 & Platform & $3^{*}$ & $\mathrm{X}$ & $X$ & $\mathrm{X}(2-\mathrm{D})$ \\
\hline CDT-3-1 & PCDTV & 3 & $\mathrm{X}$ & $\mathrm{X}$ & Not Possible \\
\hline CDT-3-2 & PCDTV & 2 & $\mathrm{X}$ & $\mathrm{X}$ & $\mathrm{X}(2-\mathrm{D})$ \\
\hline CDT-3-3 & PTV Boilerplate & 3 & $\mathrm{X}$ & $\mathrm{X}$ & $X(3-D)$ \\
\hline CDT-3-4 & PCDTV & 3 & $\mathrm{X}$ & $\mathrm{X}$ & (pending) \\
\hline CDT-3-5 & PTV Boilerplate & 3 & $\mathrm{X}$ & $\mathrm{X}$ & (pending) \\
\hline CDT-3-6 & PCDTV & 3 & $\mathrm{X}$ (interpolated) & $\mathrm{X}$ & Not Possible \\
\hline
\end{tabular}

\section{Parachute Coloring and Marking}


During the lead up to manufacturing the CPAS EDU Main parachutes, consideration was given to photogrammetric markings. The primary requirements were for each canopy to be visibly different from a distance (even when reefed) and to be asymmetric to allow location of features on the canopy (e.g. damage or roll angle). Due to long lead times and to minimize costs, only the two materials were available: natural (white) and international orange (IO). Black ink could also be used, as with earlier tests, but the patterns must be simple and the amount of ink must be minimal to contain labor costs.

A contributor to uneven performance between two Gen II parachutes during CDT-2-1 was the different colored materials at each crown (see Ref. 2). Postflight permeability tests showed that natural material was more permeable than the material dyed IO. Because the crown experiences the highest pressure, especially during reefed stages, the canopy with the orange crown had a lower porosity and visibly dominated the cluster (leading to an inadvertent skipped $2^{\text {nd }}$ stage). Photogrammetric analysis confirmed that this canopy was quantifiably larger even after both canopies disreefed to full open.

Therefore, all EDU Main parachutes have alternating white and orange patterns in groups of four gores to ensure axisymmetric uniform performance. Each EDU Main ship set consists of three different general patterns, shown in Figure 10. The first has the traditional "candy striped" pattern and the second and third are each "clocked" once or twice, respectively. A black ink mark on ring 4 indicates the location of gore 1 . Ten additional smaller black marks around ring 3 were made to aid in automatic tracking. While the orange and white patterns are repeated every ship set, the black marking scheme is adjusted to ensure each EDU Main will be unique, should canopies from different ship sets be combined in later tests.

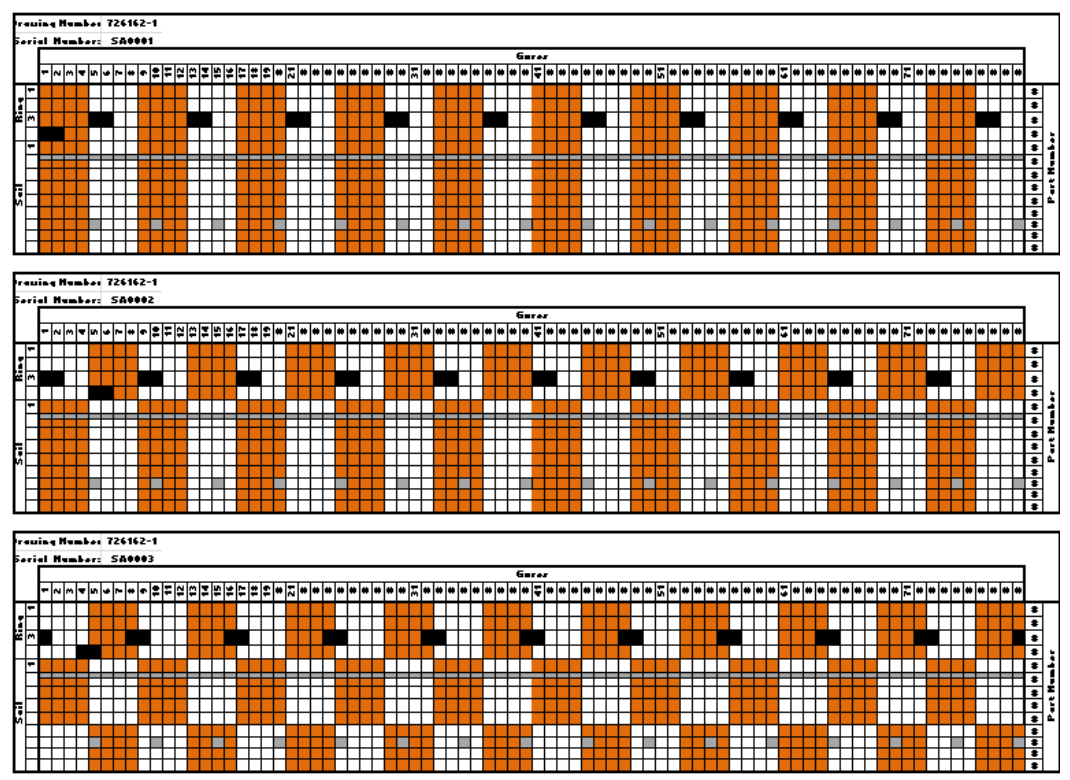

Figure 10. Markings for first three EDU Main parachutes.

\section{E. Upward-looking cameras}

In CPAS Gen I and II cluster tests, such as CDT-2-2 and CDT-23 , the Main parachutes terminated in a confluence fitting, which suspended the rectangular pallet test vehicles by harness slings, resulting in a stable platform. The current EDU test flights use vehicles which are suspend by the parachutes at a single attachment point similar to the Orion/MPCV attach point. The fixed cameras are aimed along the theoretical static hang angle, defined by the vertical line between the attachment point and the center of gravity (CG). The parachutes will appear to move as the vehicle rotates and sways. Therefore, new methods were required to define the fly-out axis. The fly-out angles, $\theta_{\mathrm{i}}$, are illustrated in Figure 11.

Some of these updated methods came about as a result of the unexpected failure of the upward-looking high definition (HD) cameras on the first EDU test, CDT-3-1. Each bullet camera mounted on the fin, or "FinCam," used a super-wide angle lens with a 178 degrees Field Of View (FOV) and produced a Standard Definition (SD) image. One of these cameras provided a view of the centers of the Main parachutes, but the image was highly distorted.

The previous lens calibration method used squares on a checkerboard pattern to map the distortion field. However, this method breaks down with highly distorted fish-eye lenses. A more generic method to calibrate lenses was described by Kannala and

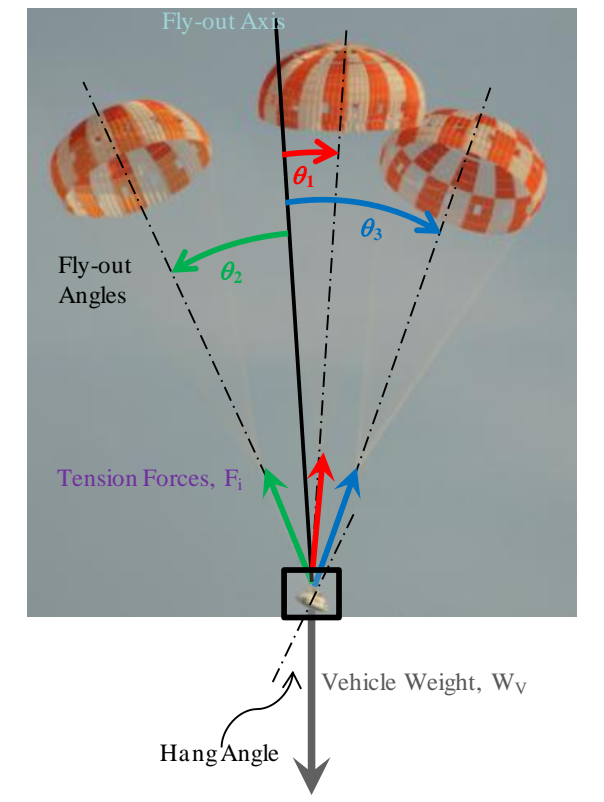

Figure 11. Fly-out angle definition for EDU tests. 
Brandt. ${ }^{9}$ This calibration method uses a target consisting of a regular pattern of circles. Kannala provided a Matlab script to determine the calibration corrections, including many asymmetric distortion terms. The original and undistorted views are shown in Figure 12.

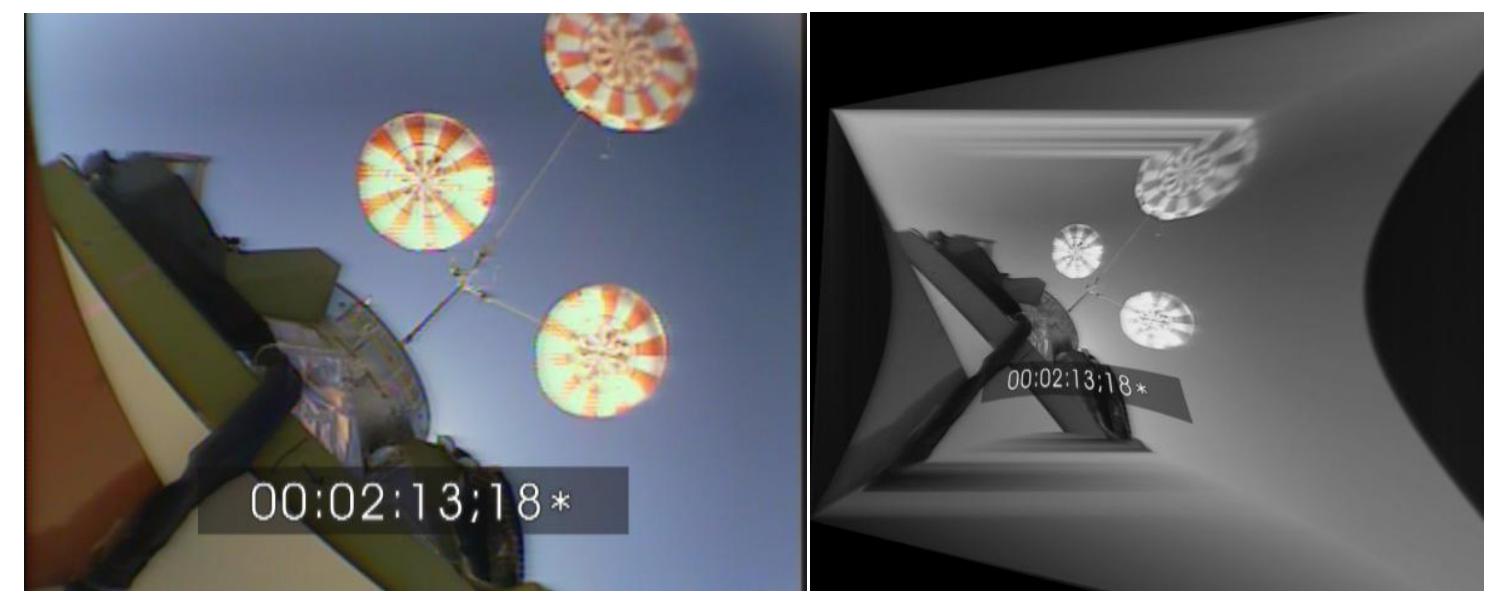

Figure 12. Original (left) and un-distorted (right) views from FinCam 2 for obtaining CDT-3-1 fly-out angles.

Although the small SD FinCam was used successfully to compute fly-out angles on CDT-3-1, the wide angle lens and low resolution were not conducive to accurately track points along the skirt.

\section{F. Fly-Out Angle Measurement}

The fly-out angles are calculated entirely in image space coordinates from the distortion-corrected imagery using perspective geometry, as shown in Figure 13. The 2-D pixel points of the center vents of each Main parachute (A, B)

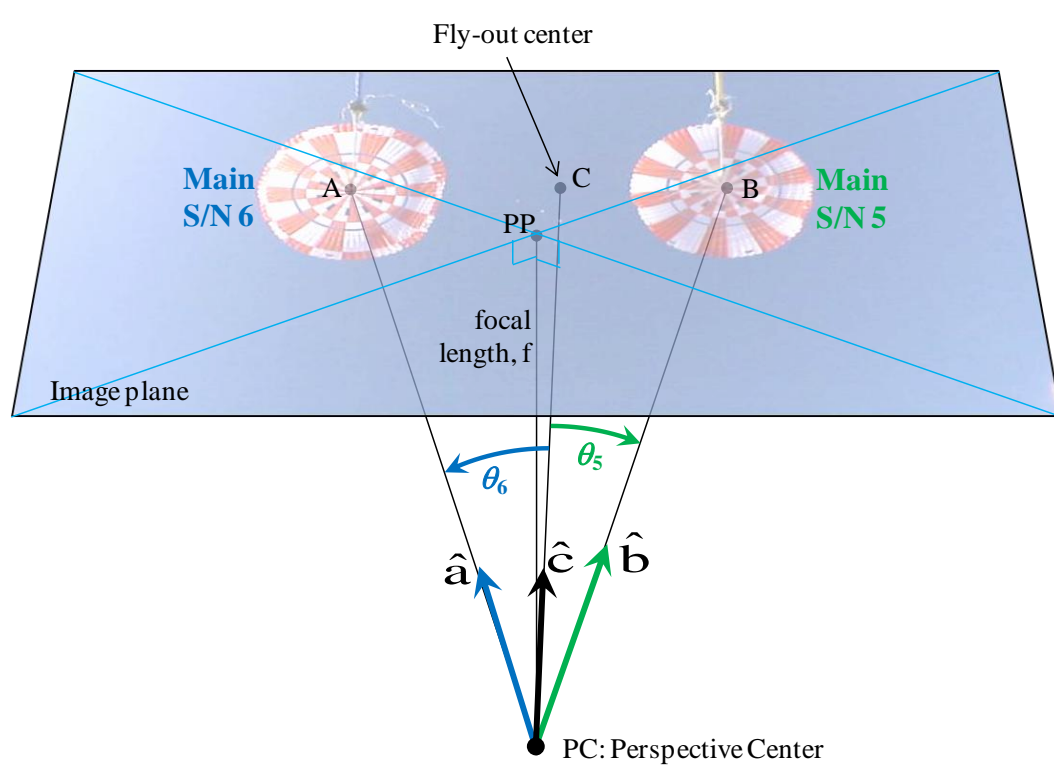

Figure 13. Fly-out angle vectors in image space. are tracked with TrackEye software. Normalized unit vectors $\hat{a}$ and $\hat{b}$ emanate from the perspective center (PC) to each vent center. The perspective center lies one focal length (f) away from the principal point (PP), in a direction perpendicular to the image. In this example, the principal point is drawn exactly at the center of the image, though in the actual cameras it was located some distance away from it.

In previous analysis, the center point, $\mathrm{C}$, was defined according to the 2-D Main vent points in the image plane. However, the new method defines the fly-out center as the 3-D vector average, $\hat{c}$, of the Main unit vectors. This is illustrated graphically in Figure 14. The fly-out angles for each Main are computed as the angle between the vector average and the corresponding unit vector. For two-Main tests, both fly-out angles will be equal. 
The current fly-out method requires that the center vent of all Mains be visible at the same time in order to compute the fly-out axis as the vector average. However, the cameras are often not pointed in the center of the cluster and parachutes leave the field of view. Optimally pointing the cameras is challenging for the current test vehicles because mass property changes will affect the static hang angle. Camera brackets are designed using pre-visualization, but often must be adjusted between flights.

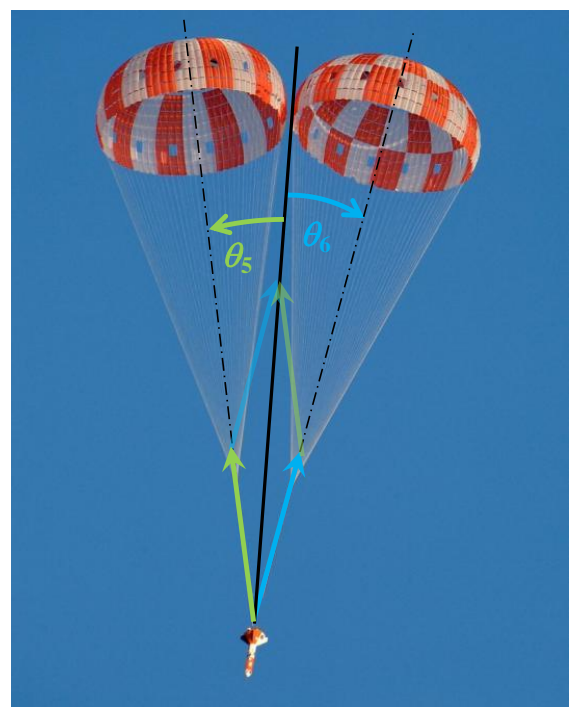

Figure 14. Fly-out axis as vector average.

An extreme case was CDT-3-6 where all three Main parachutes were periodically out of frame. A method was developed to estimate the vent location while out-of-frame by interpolating tracking data. The X vs. Y plot for each parachute is shown in Figure 15 where the colored portions are the interpolated regions. These approximations are considered adequate, but lose fidelity if the parachute in question is colliding or touching another when off screen, or if the rotation changes direction.
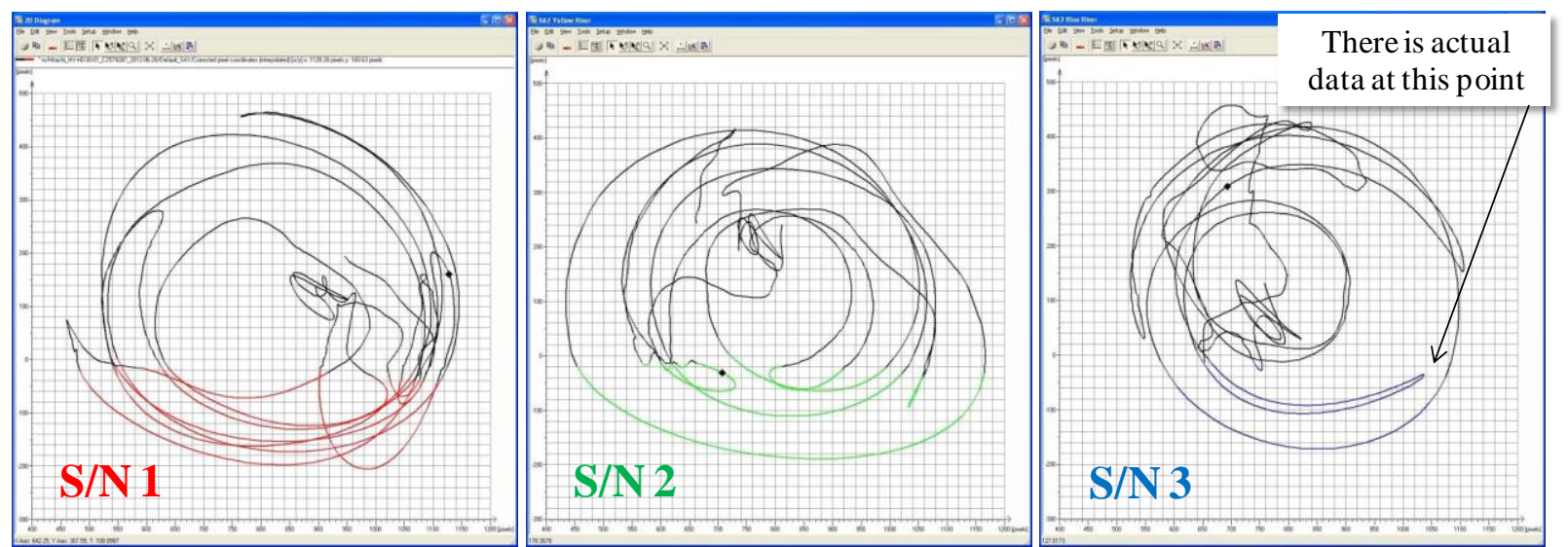

Figure 15. CDT-3-6 directly measured vent tracking (black) and interpolated regions (colored).

The resulting time histories of fly-out angle are shown in Figure 16. The cluster average, used as a metric of flyout statistics, is plotted as a black curve with the interpolated points highlighted. Parachute collisions are indicated by vertical bars, whose colors indicate which parachutes are involved in a given collision. Images of the typical cluster fly-out behavior are also shown. The largest fly-out occurs after the disreef to full open. Although the individual traces diverge, the overall periodic cluster behavior is indicated by the average. The added porosity parachutes were shown to have two general epochs, with the latter region more damped. Two of the collisions on this test are when a canopy moves in between the other two canopies, forming a straight line. These incidents are also indicated on the time history when a fly-out angle approaches zero. 
Interpolating the vent locations resulted in realistic fly-out angle histories. However, it was not practical to compute projected areas from CDT-3-6 because at least one of the parachutes was almost always at least partially out of frame due to the camera pointing angle.

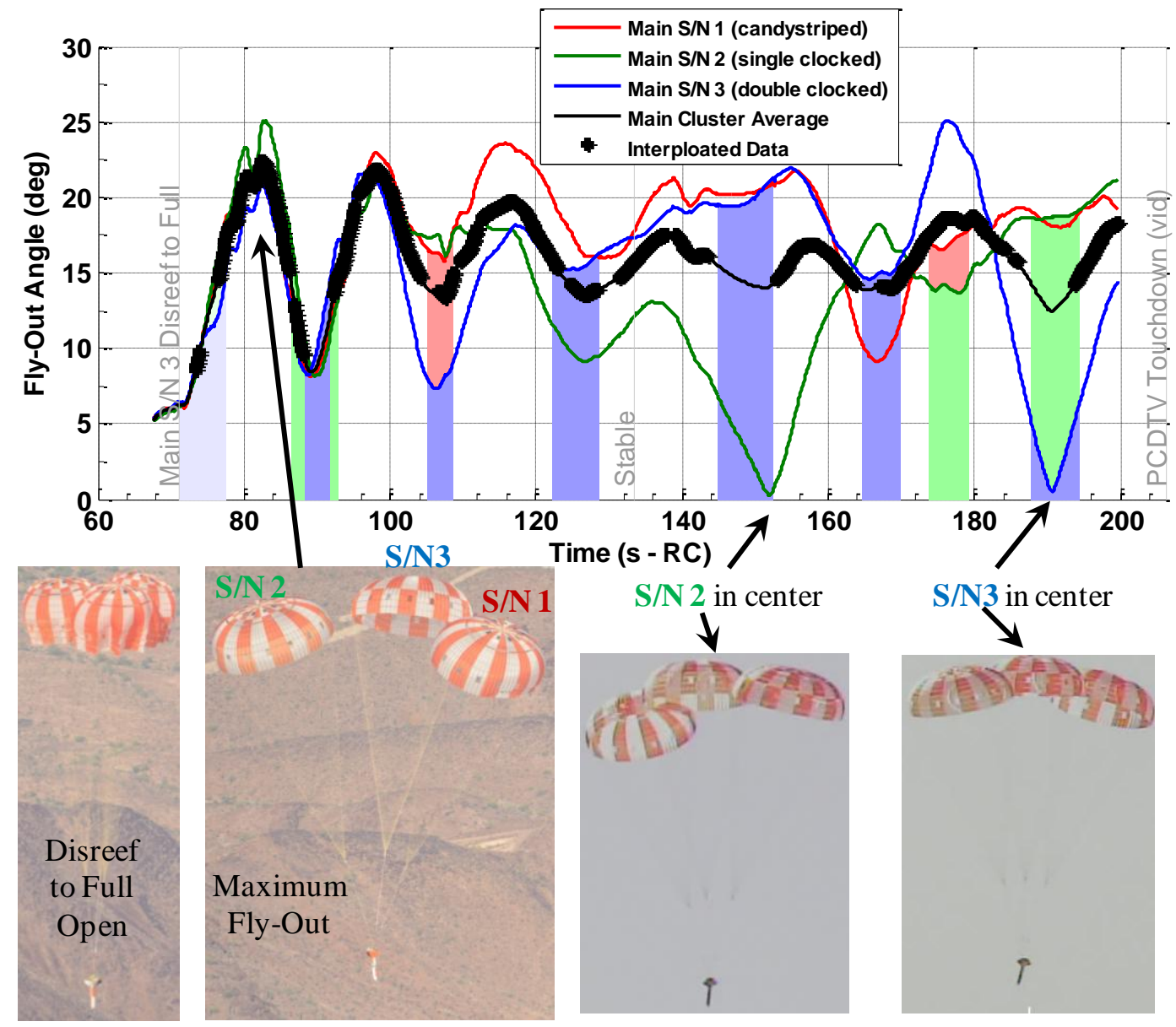

Figure 16. CDT-3-6 fly-out angles and cluster formation. 


\section{G. Projected Area Measurement}

The previous method for obtaining parachute diameters from onboard video used a direct scaling method which attempted to account for different orientations of the parachutes as they moved about. That method only works if a narrow field (long focal length) lens is used, which makes the projections close to orthographic. Perspective effects from a wide field of view lens combined with tethered motion of the parachutes distort the image of the skirt in a way that makes direct scaling impossible.

When parachutes fly out, some parts of the skirt are much closer to the plane containing the camera than others. This means the image scale is not uniform and leads to a distorted appearance of the parachute.

Radial distortions in the Fuji lenses mounted on the HD cameras counteract the perspective distortion, making the perspective effects less noticeable. A CDT3-3 video capture show in Figure 17 demonstrates the perspective effects by removing the lens distortions. The apparent size of the parachutes clearly varies in the bottom image.

As with the previous method, ten points on each skirt points are tracked in every frame using the TrackEye software. Previously, the points were assumed to lie on a flat 2-D surface. The apparent size of

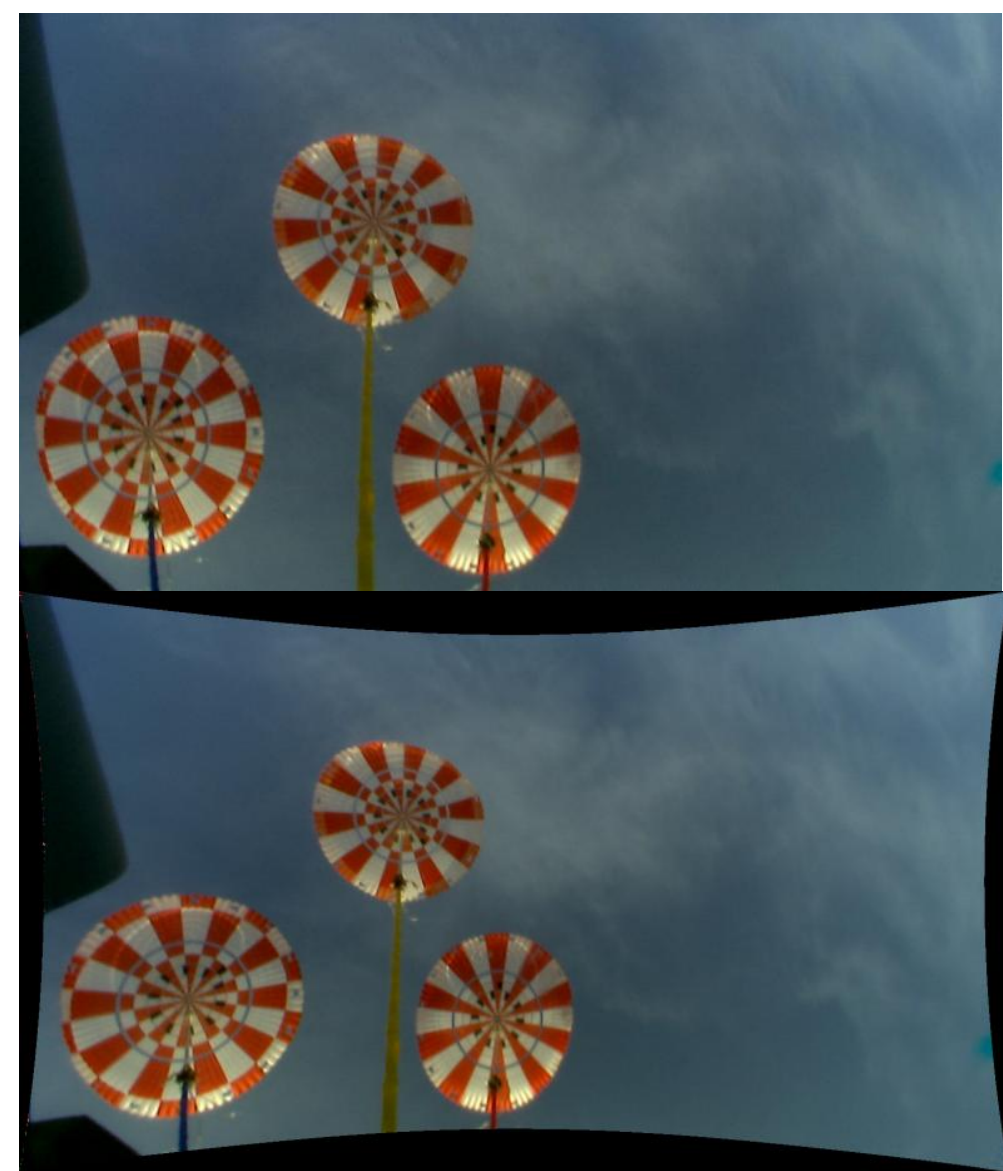

Figure 17. Unaltered upward-looking frame of CDT-3-3 (top) and frame with radial distortions removed to better show perspective distortion from tethered movement (bottom).

each skirt was computed by estimating the distance from the camera plane to the skirt, using known features at the crown as a reference. The area was computed as the sum of circular "wedge" sectors. 


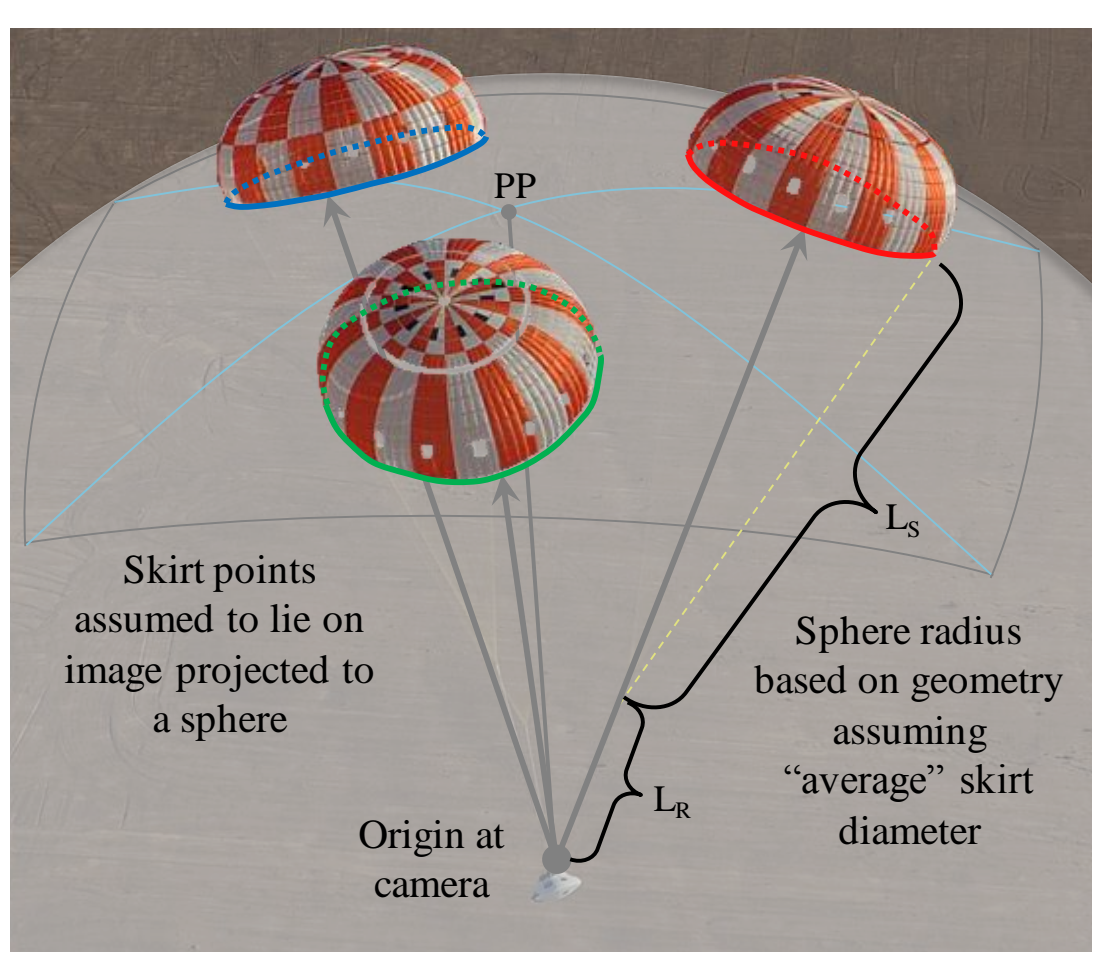

Figure 18. Spherical geometry for parachute projected area.
The new method was developed to obtain consistent areas among parachutes. As illustrated in Figure 18, this method assumes all skirt points lie on a sphere centered at the camera (which is close to the riser attachment point). The radius of this sphere is determined by known geometry. The lengths of the riser and suspension lines are known, and the suspension line half-angle is approximated for an "average" projected skirt diameter. Each tracked point on the skirt defines a vector emanating from the perspective center which intersects the spherical surface to obtain a 3dimensional point in object space relative to the camera. These 3-D points in space are then used to compute a total area for the skirt at the given time.

The desired product is a flat projected area. However, the skirt points for a given canopy will not be coplanar unless the points form a perfect circle. The previous procedure to sum up circular sectors is complicated because spherical geometry allows for polygons with internal angles summing to greater than 360 degrees. The new procedure is to first compute the 3$\mathrm{D}$ centroid (e.g. the average $\mathrm{X}, \mathrm{Y}$, and $\mathrm{Z}$ ) of all ten points. The area of each wedge section is calculated using the proportion of a circle out from the computed center. The areas of each wedge are then summed to produce the canopy projected area, $S_{p}$. The effective projected diameter, $D_{p}$, is defined from the projected area according to Eq. 2. The sum of the interior angles sometimes slightly exceeds 360 degrees during parachute collisions.

$$
\mathrm{D}_{\mathrm{p}}=\sqrt{4 \cdot \mathrm{S}_{\mathrm{p}} / \pi}
$$

The time histories of fly-out angle, perimeter, and projected diameter for each Main canopy on CDT-3-3 are plotted in Figure 19. This analysis quantifies how the collisions between parachutes due to small fly-out angles cause losses in projected area. The total projected area of the cluster has a strong correlation to the steady-state drag coefficient based on vertical rate of descent, defined in Eq. 3. ${ }^{11}$ As shown in Figure 20, losses in projected area cause strong minima in drag coefficient (plotted on the secondary axis) due to a high rate of descent. Unfortunately, the total projected area is often not available during the highest drag periods, because at least one canopy is out of frame when the cluster is furthest apart.

$$
\mathrm{C}_{\mathrm{D}_{\mathrm{o}}}=\frac{1}{\mathrm{~N}_{\mathrm{c}} \cdot \mathrm{S}_{\mathrm{o}}} \cdot\left(\frac{\mathrm{W}_{\mathrm{T}}}{1 / 2 \cdot \rho \cdot \mathrm{V}_{\mathrm{e}}^{2}}-\left(\mathrm{C}_{\mathrm{D}} \mathrm{S}\right)_{\mathrm{V}}\right)
$$


(a)

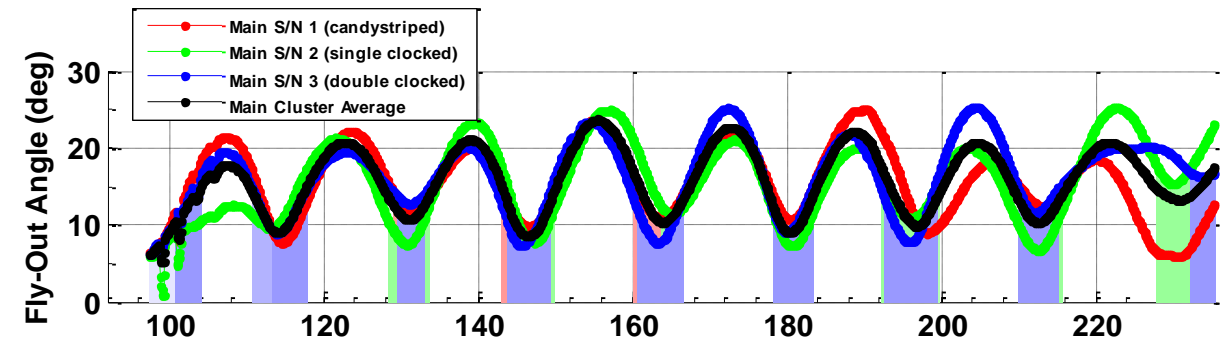

(b)

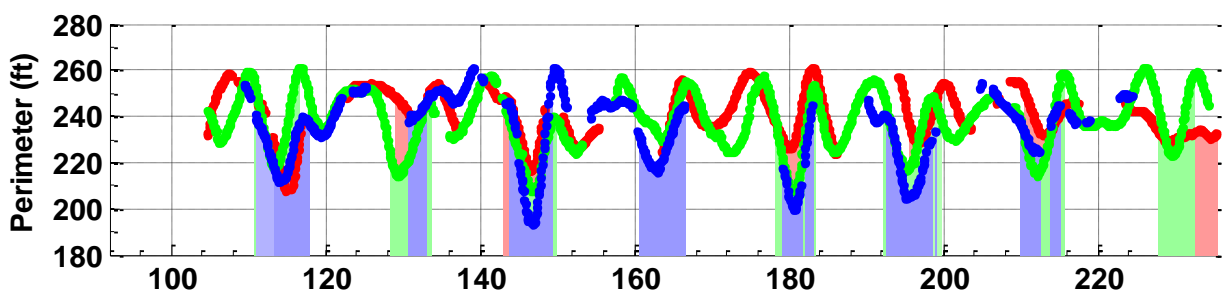

(c)

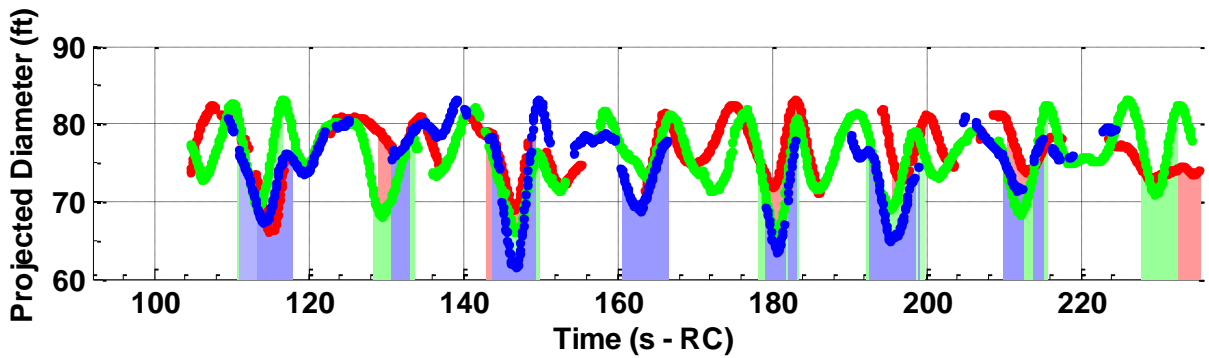

Figure 19. CDT-3-3 steady-state (a) Fly-out angles, (b) Skirt perimeters, and (c) Projected inlet diameters for each Main parachute.

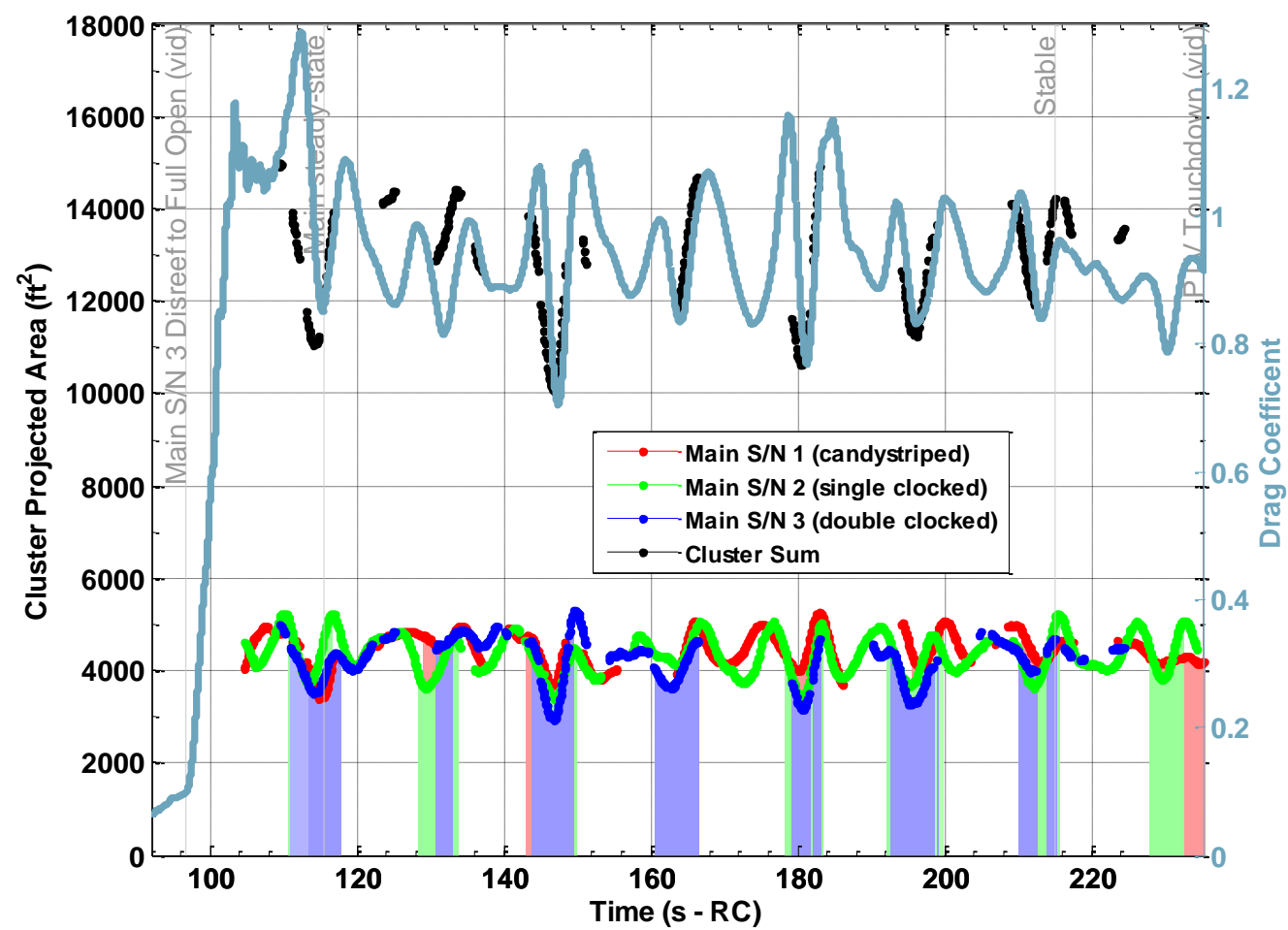

Figure 20. Relationship between cluster projected area and steady-state drag coefficient for CDT-3-3.

15

American Institute of Aeronautics and Astronautics 
Periodic signal analysis of flight test data has allowed CPAS to develop a time-varying model of fly-out angle suitable for Monte Carlo simulations. This is currently applied directly to modeling torque caused by riser twist. It is expected that similar analysis of the projected area and collisions will allow for modeling these parameters as well. Therefore, all these parameters can be combined into a time-varying model of drag coefficient and rate of descent. This will improve the fidelity of Orion simulations of roll control and splashdown impacts.

\section{Conclusion}

Several improvements have been made to the photogrammetric analysis capabilities of CPAS. High-speed cameras are used to track the mortar ejection velocity. The Main parachute fly-out angle and projected area analysis process has been updated. As the test program continues, several lessons were learned about optimizing the camera usage, installation, and settings to obtain the highest quality imagery possible.

\section{Acknowledgments}

Video configuration management, installation, and pre-visualization were conducted by the CPAS video team of Robert Rimes, Marcos Jaramillo, and Ryan Sweet.

\section{References}

${ }^{1}$ Machín, R. A., Stewart, C. E., Evans, C. T., McMichael, J. H., "Human Rating the Orion Parachute System" $21^{s t} A I A A$ Aerodynamics Decelerator Systems Technology Conference, Dublin, Ireland, May 2011, AIAA paper 2011-2502.

${ }^{2}$ Ray, E. S., Bretz, D. R., and Morris, A. L., "Photogrammetric Analysis of CPAS Main Parachutes," $21^{\text {st }}$ AIAA Aerodynamics Decelerator Systems Technology Conference, Dublin, Ireland, May 2011, AIAA paper 2011-2538.

${ }^{3}$ Fastec Imaging, "Fastec HiSpec 2 Datasheet,”[online], URL: www.fastecimaging.com [cited March 2012].

${ }^{4}$ Dryden Flight Research Center, "Dryden Aircraft: T-34C," [online], URL: http://www.nasa.gov/centers/dryden/aircraft/T34C/index.html [cited 20 December 2012].

5 Ray, E. S., "Reefing Line Tension in CPAS Main Parachute Clusters," $22^{\text {nd }}$ AIAA Aerodynamic Decelerator Systems Technology Conference, Daytona Beach, Florida, March 2013 (submitted for publication).

${ }^{6}$ Purvis, J. W. “Improved Prediction of Parachute Line Sail During Lines-First Deployment,” AIAA paper 84-0786.

${ }^{7}$ Eckroth, W., Garrard, W. L., and Miller, N., “Design of a Recovery System for a Reentry Vehicle,” AIAA paper 93-1224.

${ }^{8}$ Drozd, Vladimir, "Parachute deployment model and its application to CDT-3-1\&2 Drogue mortar velocity estimations," presented to CPAS program 12 March 2012, Airborne Systems.

${ }^{9}$ Kannala, J. and Brandt, S. S., "A Generic Camera Model and Calibration Method for Conventional, Wide-Angle, and Fish-Eye Lenses," IEEE Transactions on Pattern Analysis and Machine Intelligence, Vol. 28, No. 8, August 2006.

${ }^{10}$ Photo-Sonics, Inc., “TrackEye Motion Analysis Software,” [online], URL: http://www.photosonics.com/trackeye_software.htm [cited 13 February 2011].

${ }^{11}$ Ray, E. S., and Morris, A. L., "Measurement of CPAS Main Parachute Rate of Descent," $21^{\text {st }}$ AIAA Aerodynamic Decelerator Systems Technology Conference and Seminar, Dublin, Ireland, May 2011, AIAA paper 2011-2545. 